\title{
Do you think they know about us? oral and maxillofacial surgery in Hong Kong
}

\begin{abstract}
Despite the tremendous increase in public awareness regarding personal health, the specialty of oral and maxillofacial surgery (OMFS) is still unknown to many. This is the first survey to analyze the public awareness regarding the specialty of OMFS in Hong Kong. It aims to point out the situation and arouse the responsible bodies' action accordingly. Their objectives should be aim at promoting the specialty to the public, to help fully unitizing the services available, and to encourage more people to take the opportunity to be trained, in turn more people can become part of our team. Questionnaires were sent out randomly through personal network by helpers recruited. Among the 104 interviewees, there were 78 who $(75 \%)$ claimed they had never heard of the specialty of OMFS, while the other $26(25 \%)$ reported that they had heard of it. Within the 26 people who heard of OMFS, $14(54 \%)$ said that they did not actually know what OMFS was about, while the other 12 $(46 \%)$ claimed that they had knowledge about OMFS to a certain extent. In summary, there is a very low awareness in OMFS to the general public in terms of its scope of service, the provision of service and training by the government and institutes. It is very discouraging to learn that most of the people do not really know us as they may miss the chance to be treated or to be trained.
\end{abstract}

Keywords: oral and maxillofacial surgery, survey, awareness
Volume I Issue 2 - 2014

Lau SL

Dental Implant and Maxillofacial Center, Hong Kong

Correspondence: Lau SL, Specialist in Oral and Maxillofacial Surgery, Dental Implant and Maxillofacial Center, Room 1901, The Center. 99 Queen's Road Central, Hong Kong, Tel 28514888,Email fedled@hotmail.com

Received: April 29, 2014 | Published: May 30, 2014
Abbreviations: OMFS, oral and maxillofacial surgery; ENT, ear, throat and nose; TMJ, temporomandibular joint

\section{Introduction}

People nowadays are more conscious about healthcare related issues as reflected by the blooming of a lot of commercials on televisions, signboards and magazines. More and more doctors were being interviewed through these media, as there is a great demand for the public to know more about their health. Dentistry is a little bit slow in this area, due to their relative conservativeness over publicity and advertisements. Despite the tremendous increase in public awareness regarding personal health, the specialty of oral and maxillofacial surgery (OMFS) is still unknown to many. OMFS receives referrals from both dental and medical specialties as well as emergency department. It acts as a bridge to a lot of different fields across the dental and medical borders. However, it has been reported that there was a low awareness of this field to both the general public and professionals in other countries..$^{1-4}$ Hong Kong Chinese are thought to be unexceptional. The reasons may be due to the traditional thinking that oral health is not as important, and people will not seek help until symptoms affects their daily life to an unbearable extend.

This is the first survey to analyze the public awareness regarding the specialty of OMFS in Hong Kong. It aims to point out the situation and arouse the responsible bodies' action accordingly. Their objectives should be aim at promoting the specialty to the public, to help fully unitizing the services available, and to encourage more people to take the opportunity to be trained, in turn more people can become part of our team.

\section{Methodology}

Questionnaires were sent out randomly through personal network by helpers recruited. The helpers gave out the questionnaire randomly to the people they met on a specific day. These questionnaires were only distributed to Hong Kong citizens who aged 18 years or above. The subjects, who were neither dental nor medical related personnel, were interviewed individually by helpers.

The questionnaires were made up of three parts, including 12 simple questions. Personal demographic data were recorded in the first part. Second part included general questions about OMFS including the scope of service and training particulars. The final part was designed to test the knowledge of the interviewees, whether they could correlate some specific diseases or conditions that could be treated by oral and maxillofacial (OMF) surgeons.

\section{Results}

There were 150 questionnaires distributed to 20 helpers in June 2011, where 104 were completed through personal interview to nondentally and non-medically related Hong Kong citizens. There were $59(57 \%)$ females and 45 males (43\%). The mean age was 32 yearold, ranging from 18 to 65 year-old.

Among the 104 interviewees, there were 78 who (75\%) claimed they had never heard of the specialty of OMFS, while the other 26 $(25 \%)$ reported that they had heard of it. Within the 26 people who heard of OMFS, $14(54 \%)$ said that they did not actually know what OMFS was about, while the other $12(46 \%)$ claimed that they had knowledge about OMFS to a certain extend (Figure 1). They were asked on how they knew about OMFS. There were five ways reported, including from friends/ family members (65\%), newspaper/ magazine $(15 \%)$, television $(12 \%)$, radio $(4 \%)$ and medical/ healthcare related magazine (4\%) respectively.

Five questions were asked regarding the training and services of OMFS available in Hong Kong. There were different thoughts regarding the stream of field that OMFS belonged to (Figure 2). A majority (44\%) knew that OMFS belonged to the field of dentistry 
while $39 \%$ thought that it belonged to medicine. There were 33 interviewees (32\%) had a correct idea of the fact that there were around 50 OMFS specialists in Hong Kong. The rest had overestimated the amount of OMFS specialists in which $34(33 \%)$ thought that there were around $150,21(20 \%)$ said that there were around 250 and $16(15 \%)$ thought that there were around 350 (Figure 3). Regarding the training pathway, only $8(7.8 \%)$ had correctly pointed out that there was a minimum of six years training after the primary degree. Most of the people had under estimate the training period, in which $83.6 \%$ thought it required less than six years of training. Only $3.8 \%$ thought that it required more than six years, where the rest of the people $(4.8 \%)$ claimed that they did not know. The University of Hong Kong is the only tertiary institute who provide the training of OMFS specialists. There were $69 \%$ of interviewees correct about this, where $16 \%$ thought that other universities provide it and $18 \%$ said they did not know. Regarding service provision in the field of OMFS by the government sector, 38 (37\%) knew that was available, while 21 $(20 \%)$ did not. A majority (43\%) was uncertain about this.

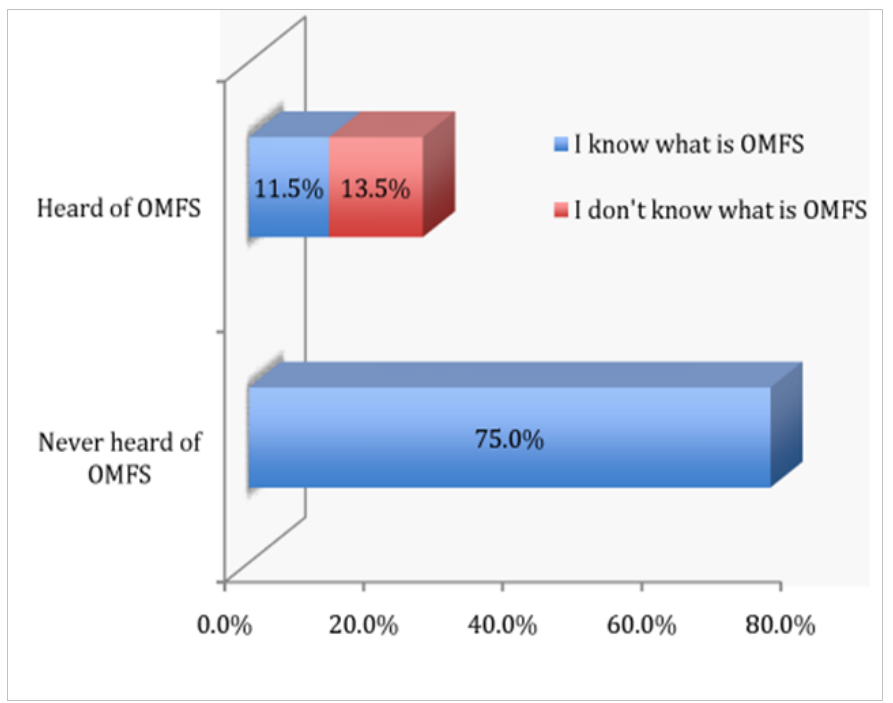

Figure I Have you ever heard of OMFS?

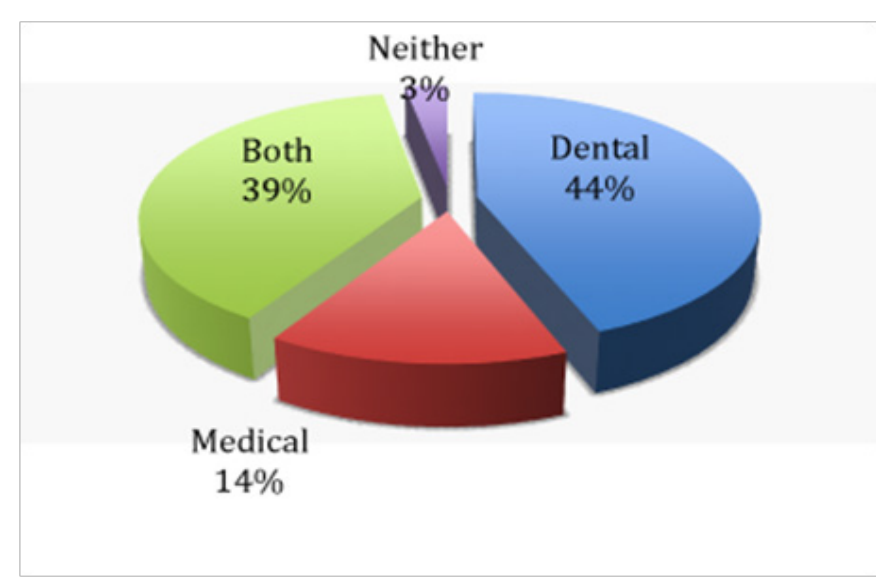

Figure $\mathbf{2}$ Which stream do you think OMFS belongs to?

There were about one third (32\%) of answers wrongly named the scope of service within OMFS. These included general dentistry $(18.9 \%)$, dental scaling $(8.7 \%)$ and orthodontics (4.4\%). Among the correct answers, most of the people knew that OMFS specialists did facial cosmetic surgeries (18.4\%) and jaw correction surgeries $(15.5 \%)$, followed by intra-oral surgeries $(15 \%)$. The results are summarized in Figure 4. Multiple choices are given to interviewees on where they would refer themselves to if they were diagnosed to have a certain disease or condition. Choices included OMF surgeons; ear, throat and nose (ENT) surgeons; general surgeons; head and neck surgeons and plastic surgeons. The answers are summarized in Table 1.

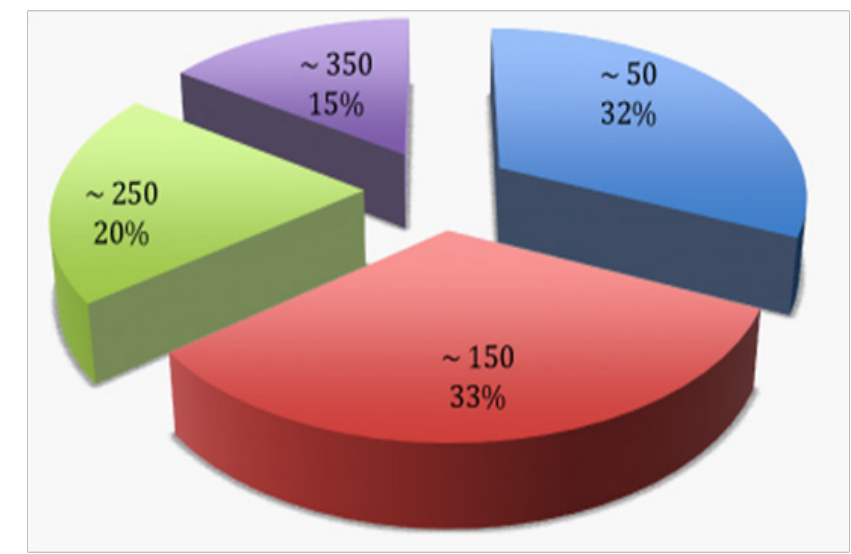

Figure 3 How many specialists in OMFS do you think there are in Hong Kong?

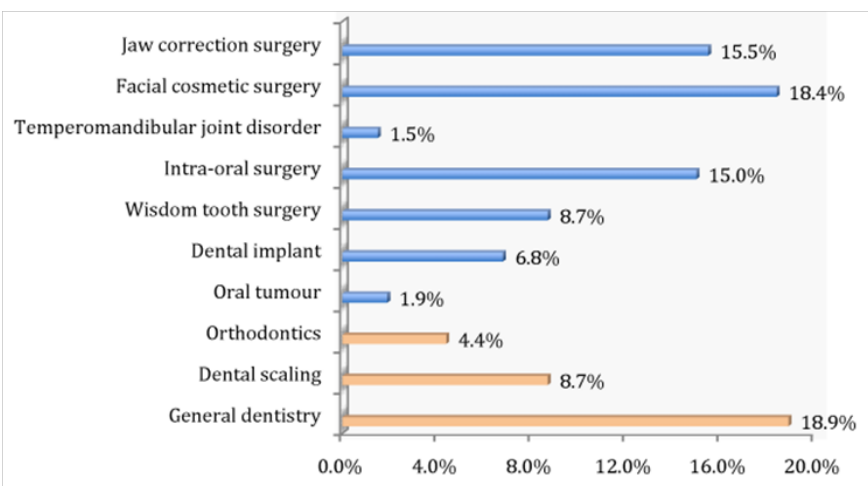

Figure 4 Can you name what the OMF surgeons do?

\section{Discussion}

Although OMFS is a branch of dentistry, it is the only specialty that bridges to the medical community so closely. It is not compulsory in Hong Kong for OMFS specialists to obtain a medical degree, but in some other countries it is a must. Current trend shows that a full medical degree is not that necessary for OMFS specialists to practice with competency. Some of the European countries are trying to trim down the training pathway especially in the medical course, trying to incorporate the essential medical part into an integrated OMFS training curriculum, so that one should no longer take another full medical training. OMFS specialists are qualified to treat not only dento-alveolar surgeries, but also a full scope of jaws and facial surgeries including facial fractures, congenital facial deformities, temporomandibular joint (TMJ) disorders, pathologies related to the jaws, salivary gland diseases, and facial reconstructions with extra-oral bone or soft tissue harvesting. With adequate training or, in some situations, collaborating with other specialties, the scope 
could be expanded to cranial-facial reconstructions, oncology and reconstructions using local or distant microvascular free flaps. Although the specialty involves in the treatment of a lot of important conditions or diseases, it is disappointed to see the lack of awareness from the general public. It was reported that there were only $11.5 \%$ who had ever heard of and knew what OMFS was.

Table I Public perception of some disease/ condition which should be treated by different specialties

\begin{tabular}{|c|c|c|c|c|c|c|c|c|c|c|c|c|}
\hline & \multicolumn{2}{|c|}{$\begin{array}{l}\text { Oral and } \\
\text { Maxillofacial } \\
\text { Surgeons }\end{array}$} & \multicolumn{2}{|c|}{ ENT Surgeons } & \multicolumn{2}{|c|}{$\begin{array}{l}\text { General } \\
\text { Surgeons }\end{array}$} & \multicolumn{2}{|c|}{$\begin{array}{l}\text { Head } \\
\text { and Neck } \\
\text { Surgeons }\end{array}$} & \multicolumn{2}{|c|}{$\begin{array}{l}\text { Plastic } \\
\text { Surgeons }\end{array}$} & \multicolumn{2}{|c|}{ Don't Know } \\
\hline & $\mathbf{N}$ & $\%$ & $\mathbf{N}$ & $\%$ & $\mathbf{N}$ & $\%$ & $\mathbf{N}$ & $\%$ & $\mathbf{N}$ & $\%$ & $\mathbf{N}$ & $\%$ \\
\hline Oral Ulceration & 62 & $59.6 \%$ & 13 & $12.5 \%$ & 29 & $27.9 \%$ & 0 & $0.0 \%$ & 0 & $0.0 \%$ & 0 & $0.0 \%$ \\
\hline Oral Malignancy & 65 & $62.5 \%$ & 17 & $16.3 \%$ & 18 & $17.3 \%$ & 3 & $2.9 \%$ & I & $1.0 \%$ & 0 & $0.0 \%$ \\
\hline Tongue Tumor & 50 & $48.1 \%$ & 28 & $26.9 \%$ & 17 & $16.3 \%$ & 5 & $4.8 \%$ & 3 & $2.9 \%$ & I & $1.0 \%$ \\
\hline TMJ Disorder & 48 & $46.2 \%$ & 4 & $3.8 \%$ & 16 & $15.4 \%$ & 28 & $26.9 \%$ & 8 & $7.7 \%$ & 0 & $0.0 \%$ \\
\hline Jaw Fracture & 31 & $29.8 \%$ & 0 & $0.0 \%$ & 15 & $14.4 \%$ & 35 & $33.7 \%$ & 29 & $27.9 \%$ & 4 & $3.8 \%$ \\
\hline $\begin{array}{l}\text { Salivary Gland } \\
\text { Pathology }\end{array}$ & 48 & $46.2 \%$ & 26 & $25.0 \%$ & 18 & $17.3 \%$ & 8 & $7.7 \%$ & 4 & $3.8 \%$ & 0 & $0.0 \%$ \\
\hline Dental Implant & 78 & $75.0 \%$ & 2 & $1.9 \%$ & 9 & $8.7 \%$ & 3 & $2.9 \%$ & 10 & $9.6 \%$ & 2 & $1.9 \%$ \\
\hline $\begin{array}{l}\text { Cleft Lip and } \\
\text { Palate Repair }\end{array}$ & 30 & $28.8 \%$ & 1 & $1.0 \%$ & 3 & $2.9 \%$ & 13 & $12.5 \%$ & 57 & $54.8 \%$ & 0 & $0.0 \%$ \\
\hline Jaw Tumor & 27 & $26.0 \%$ & 8 & $7.7 \%$ & 14 & $13.5 \%$ & 44 & $42.3 \%$ & 10 & $9.6 \%$ & I & $1.0 \%$ \\
\hline Facial Swelling & 23 & $22.1 \%$ & 4 & $3.8 \%$ & 40 & $38.5 \%$ & 12 & $11.5 \%$ & 15 & $14.4 \%$ & 10 & $9.6 \%$ \\
\hline $\begin{array}{l}\text { Dentofacial } \\
\text { Deformity }\end{array}$ & II & $10.6 \%$ & 0 & $0.0 \%$ & 1 & $1.0 \%$ & 4 & $3.8 \%$ & 87 & $83.7 \%$ & I & $1.0 \%$ \\
\hline
\end{tabular}

OMFS was introduced to a majority of people $(65 \%)$ by a friend or a family member. This indicates that most of the knowledge was by personal experiences of people around. There was almost no public image about this specialty. The government or tertiary institute could publicize this field by media like TV, radios or newspapers through interviews or in terms of case study. The local association should also take a leading role to arouse the public awareness regarding our specialty, either by organizing public talks or distributing leaflets / booklets / magazines regularly.

There are $83 \%$ of interviewees answered correctly that OMFS belongs to the field dentistry or both dentistry and medicine. It is not surprising as the name OMFS itself indicated that is something about the oral cavity, thus dentistry. There are 51 registered OMFS specialists currently in Hong Kong. ${ }^{5}$ When compared to other medical specialties, we have relatively few colleagues. Only $32 \%$ of the interviewees had the correct impression about the amount of specialists available in Hong Kong while the rest had overestimated the amount with $15 \%$ said that there were around 350 .The small amount of registered specialists may explain in part the relative low public awareness.

Regarding the scope of service in OMFS, around one third of people misunderstood what we did (Figure 4). Although the others could name some of the treatments that we provided, a lot were being unknown to them. Most of the people had stated we provided facial cosmetic surgeries $(18.4 \%)$, jaw correction surgeries $(15.5 \%)$ and intra-oral surgeries $(15 \%)$. This may not truly reflect the knowledge about the scope in OMFS. Oral and maxillo- and facial surgery itself is self-explanatory. May be the interviewees were just guessing the answer.
Table 1 summarized some conditions/ diseases which could be treated by different specialties. In fact OMF surgeons could treat all of the listed conditions. Although there are overlapping responsibilities over some specialties, there are never absolute right or wrong on who should do what. It all depends on the training they have received and the culture in different places. The results indicate only on how the general public thought when they came across these diseases. A majority $(59.6 \%)$ thought that OMF surgeons should treat oral ulceration over other specialties. Moreover, it was reported similarly that, most of the people thought an OMF surgeon should treat oral malignancy $(62.5 \%)$ and tongue tumor (48.1\%). In my personal experience, most of these cases would go to either ENT surgeons or head and neck surgeons. In real life, it depends a lot on who was referring the cases. A dental practitioner would mostly refer these cases to OMF surgeons, while a medical practitioner would do it differently. This may be the explanation on the reported high percentage of seeking OMF surgeons over these cases while in the real life it is not the truth. The reason lies on the amount of medical practitioners are far more than dental practitioners in Hong Kong.

TMJ disorder is rather a vague area for both practitioners and patients. The reason of this is the fact that these joints involve a lot of different structures and usually the symptom is indistinct in terms of location and soreness. Most of the patient came in with a history of seeking different doctors already without treating the problems; however most of the patients (46.2\%) would prefer an OMF surgeon. Jaw fractures are a unique condition for OMF surgeons, as it involves most of the time teeth and occlusion. However head and neck surgeons ranked first $(33.7 \%)$ in patients mind, followed by OMF surgeons $(29.8 \%)$ and plastic surgeons $(27.9 \%)$. Jaw tumor is a similar entity, as it involves surgery and reconstruction of the jaw. As such, 
the pattern was reported similarly that head and neck surgeons ranked first (42.3\%), followed by OMF surgeon (26\%).

Dental implant is absolutely a scope of OMF surgeons within the list. Very interestingly, around $10 \%$ of people felt that plastic surgeons would do that. Probably, most of the time, it involves a cosmetic concern, especially at the anterior esthetic zone of the dentition. Cleft lip and palate repair surgeries involves mostly plastic surgeons as well as OMF surgeons. The results showed that $54.8 \%$ thought the plastic surgeons should be responsible for this while $28.8 \%$ thought of OMF surgeons. Dentofacial deformity involves the facial cosmetic as well as functional problem of patients. Treatment includes orthodontics before the jaw could be moved surgically to a better position. To achieve an ideal occlusion is one of the most important objectives in the treatment of these situations. Although not as obvious as dental implant, orthognathic surgery is again one of the most unique surgeries that OMF surgeons do. Results showed that over $80 \%$ of people would seek plastic surgeons for this kind of treatment, while only around $10 \%$ would seek OMF surgeons. Although some plastic surgeons would do this kind of surgery, still this is a main area in OMFS. This again reflects the poor awareness of OMFS among general public. Lastly, facial swellings may indicate a lot of different problems, as it can be originates from anywhere around the face, jaws, teeth, ear, sinus, eyes, etc. Around $10 \%$ of people did not know who to seek help from, and this was the condition that confused patients the most. These results indicated a lot of people were actually unaware of what OMFS specialists could help them if they got a relevant disease. Even it was within the scope of OMFS, they would prefer other specialties more.

The training pathway of OMFS specialists include a minimum of six years supervised training under recognized training centers. It comprises of three years of basic training after the dental degree, following another three-year period of advanced training. There is an intermediate examination in between and an exit examination on finishing all the training. The College of Dental Surgeons of Hong Kong is the responsible body of specialist training in Hong Kong, and it is under the umbrella of The Hong Kong Academy of Medicine. The specialist training pathway is in a sense similar to other medical specialties. The results indicate most of the general public $(83.6 \%)$ has underestimated the training requirement in terms of time. This reflects either they have a general lack of knowledge on how specialists are being trained in Hong Kong or they have under estimate on the scope of service we can provide, as reflected in the latter part of the results. The University of Hong Kong is the only tertiary institute who provides such training, as there is only one dental school in Hong Kong. 69\% were correct about this. There are also recognized training centers from the government sectors, but it is of minority. The government sector does provide public service in OMFS. Either it could be a referral from private practitioners or the public can go to queue up in a government outpatient unit before they are being referred. Only 37\% reported they had knowledge about this.

This shows the lack of knowledge from the general public, regarding the training opportunity and the provision of service by government sector. Lack of awareness will in turn reduce the amount of people who can enjoy the service, or reduce the chance of being trained. The government and the university should think over again in how to fully unitize the resources being input, or else it will be a waste of effort. This lack of awareness affects the dynamic of the whole system, not only to the patients or to the public, but also to the doctors who provide the treatment, the trainers who train residents and all the personnel who are being involved.

In summary, there is a very low awareness in OMFS to the general public in terms of its scope of service, the provision of service and training by the government and institutes. It is very discouraging to learn that most of the people do not really know us as they may miss the chance to be treated or to be trained. There is no doubt that the specialty deserves a better public awareness. The stress should be put on three areas, namely the public image of who we are, awareness of the treatment we could provide, the awareness of the details of training pathways and opportunities. The objectives are to let more people know who they should seek help from and provide open opportunities for people to be trained.

\section{Acknowledgments}

None.

\section{Conflict of interest}

The author declares that there is no conflict of interest.

\section{References}

1. Ameerally P, Fordyce AM, Martin IC. SO you think they know what we do? The public and professional perception of oral and maxillofacial surgery. Br J Oral Maxillofac Surg. 1994;32(3):142-145.

2. Hunter MJ, Rubeiz T, Rose L. Recognition of the scope or oral and maxillofacial surgery by the public and health care professionals. $J$ Oral Maxillofac Surg. 1996;54(10):1227-1232.

3. Ifeacho SN, Malhi GK, James G. Perception by the public and medical profession or oral and maxillofacial surgery--has it changed after 10 years? Br J Oral Maxillofac Surg. 2005;43(4):289-293.

4. Subhashraj K, Subramaniam B. Awareness of the specialty of oral and maxillofacial surgery among health care professional in Pondicherry, India. J Oral Maxillofac Surg. 2008;66(11):2330-2334.

5. http://www.dchk.org.hk/docs/SB_Oral_and_Maxillofacial_Surgery.pdf 